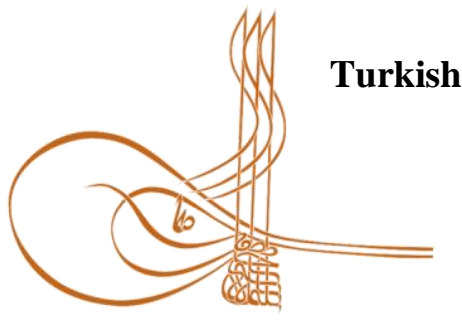

www.turkishstudies.net/appliedsciences
eISSN: 2667-5633

Research Article / Araştırma Makalesi

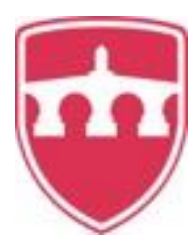

INTERNATIONAL

BALKAN

UNIVERSITY

Sponsored by IBU

\title{
Makine Öğrenme Algoritmaları ile Karaciğer Hastalığının Teşhisi*
}

Diagnosis of Liver Disease with Machine Learning Algortihms

\author{
Aytürk Keleş $^{* *}$ - Özden Burcu Kaslı ${ }^{* * *}$ - Ali Keleş ${ }^{* * * *}$
}

\begin{abstract}
Liver diseases are among quite common diseases seen worldwide. Liver diseases can pose great dangers in the body. For these reasons, liver disease Nonalcoholic fatty liver, alcoholic liver fatty, hepatitis A, hepatitis B, hepatitis C, hepatitis D, liver enlargement, liver cancer, liver and intrahepatic bile duct cancer, liver failure and cirrhosis as early as possible diagnosis and its treatment is vital. Traditional diagnostic methods are still used in medicine. However, today, thanks to the developing artificial intelligence technologies, powerful tools can be provided to support physicians in disease diagnosis, detection and treatment processes. In this study, using WEKA data mining tool by means of J48, Logistic Model Tree (LMT), Decision Stump, Hoeffding Tree, REP Tree, Random Forest, Random Tree and IBk machine learning algorithms are studied on Liver Patient Data Set (ILPD). With these algorithms, the best diagnostic result was tried to be reached. In order to evaluate the performance and success of the machine learning algorithms used in the study, firstly the confusion matrices were created and then the calculations were made according to the accepted values of the general validity in medicine. Performances of these algorithms on ILDP data set were calculated according to accuracy, sensitivity, specificity, ROC, MCC, recall, precision and F-Measure criteria respevtively. The best models obtained from machine learning algorithms can be used to create inference engines of intelligent systems to be developed for diagnosis and treatment. The obtained models have potential to create substructure of a smart system that enable to be detected the worldwide common liver diseases in early phase in all health institutions.
\end{abstract}

\footnotetext{
* Bu makale Özden Burcu KARSLI'nın yüksek lisans tezinden hazırlanmıştır.

** Doç. Dr., Ağrı İbrahim Çeçen Üniversitesi, Eğitim Fakültesi, Bilgisayar ve Öğretim Teknolojileri Eğitimi Bölümü

Assoc. Prof. Dr., Agri Ibrahim Cecen University, Faculty of Education, Department of Computer and Education Technologies Education

ORCID 0000-0001-9755-295X

ayturkk@hotmail.com

*** Öğretmen, MEB, Ağrı Şehit Korgeneral İsmail Selen Ortaokulu

Teacher, Republic of Turkey Ministry of National Education

ORCID 0000-0002-2176-9703

ozdenkarsli@hotmail.com

***** Doç. Dr., Ağrı İbrahim Çeçen Üniversitesi, Eğitim Fakültesi, Bilgisayar ve Öğretim Teknolojileri Eğitimi Bölümü

Assoc. Prof. Dr., Agri İbrahim Cecen University, Faculty of Education, Department of Computer and Education

Technologies Education

ORCID 0000-0002-0785-9593

alakmus@hotmail.com

Cite as/ Atıf: Keleş, A., Kaslı, Ö.B., Keleş, A. (2020). Makine öğrenme algoritmaları ile karaciğer hastalığının teşhisi, Turkish Studies-Applied Sciences, 15(1), 75-83. https://dx.doi.org/10.29228/TurkishStudies.39612

Received/Geliş: 05 November/Kasım 2019 Checked by plagiarism software

Accepted/Kabul: 25 March/Mart $2020 \quad$ Published/Yayın: 30 March/Mart 2020

Copyright $($ INTAC LTD, Turkey

CC BY-NC 4.0
} 


\section{Structured Abstract: Intruduction}

The liver is an active and complex organ that performs many tasks in the human body. It serves many critical functions including metabolism of drugs and toxins, removing degradation products of normal body metabolism and synthesis of many important proteins and enzymes.

Liver diseases are among the most common diseases worldwide. Liver diseases can pose great dangers in the body. For these reasons, liver disease Nonalcoholic fatty liver, alcoholic liver fatty, hepatitis $\mathrm{A}$, hepatitis $\mathrm{B}$, hepatitis $\mathrm{C}$, hepatitis $\mathrm{D}$, liver enlargement, liver cancer, liver and intrahepatic bile duct cancer, liver failure and cirrhosis as early as possible diagnosis and its treatment is vital.

It is seen that Artificial Intelligence technologies, which have been used with great success in many fields in recent years, are being used frequently in the diagnosis, treatment and diagnosis processes of diseases, especially in the field of medicine. The most important reason for this is the power of machine learning algorithms, which are under the AI technologies and Data Mining accepted as an important part of it, to reveal hidden relationships between patterns. In this way, significant achivements can be obtained in the diagnosis of diseases that exhibit similar symptoms. In this study, machine learning algorithms for the diagnosis of liver diseases were studied and the results of the algorithms have been compared with the studies in this field.

\section{Methods}

The data set used in this study has a public access in the UCI Machine Learning Repository database (Indian Liver Patient Dataset ILPD-http://archive.ics.uci.edu/ml/index.php). This data set consists of 583 patient records. 416 of these patients are liver patients and 167 of them are other patients. The data set was collected in the north east of Andhra Pradesh, India. This data set includes 441 male patient records and 142 female patient records. While 324 of male patients are liver patients, 92 of female patients are liver patients.

In the dataset consist of 11 features (age, gender, total bilirubin, Direct Bilirubin, Alkaline Phosphotase, Alamine Aminotransferase, Aspartate Aminotransferase, Total Proteins, Albumin, Ratio Albumin and selector field). The last feature of the data set contains the result of diagnosis patient.

The data set have been cleaned from out layers and the sample has missing value dropped. In last step we used SMOTE filter and some normalization algorithms to normalize data. In the state of train end test was used "10 fold Cross Validation" technique.

There are a number of some common criteria used to evaluate the performance and success of the model obtained as a result of the classification process of a machine learning algorithm used on the data set. In this study, confusion matrix was used to calculate general valid criteria. Confusion matrix, also known as error matrix, is a $2 \times 2$ matrix that provides information about the accuracy of the predictions. It allows comparing the true values of the model resulting from the classification with the predicted values.

A confusion matrix has been created for validation of each different machine learning algorithm. Some certain criteria by using these matrix values have been calculated to demonstrate the performance of algorithms. These criteria are Accuracy, Sensitivity, Specificity, ROC (Receiver Operating Characteristics), MCC (Matthews Correlation Coefficient), Recall, Precision, F-Measure respectively.

J48, Logistics Model Tree (LMT), Decision Stump, Hoeffding Tree, REP Tree, Random Forest, Random Tree and IBk machine learning algorithms, which are included in the WEKA data mining program, were studied on the ILPD data set. Classification performances of these algorithms in other word diagnostic powers were calculated and compared separately the evaluation criteria used in medicine.

\section{Results}

The results of obtained from each machine learning algorithms have been showed in Table 4. When the table is examined, it is seen that the average accuracy values of all algorithms are above $74 \%$. The random forest algorithm has the highest accuracy with $81.9 \%$. The closest following of this algorithm is the IBk algorithm and gives the second best result with $81.6 \%$. In this study, J48, LMT and Random Tree algorithms rank third with $74 \%$ accuracy values. Hoeffding Tree is fourth with $69.1 \%$ accuracy and Decision Stump is the last with $67.1 \%$. 
When all algorithms are evaluated according to the sensitivity criteria, the algorithm that gives the best result is the Random Forest algorithm with a value of $76 \%$. Random Tree with $72 \%$ and REP Tree algorithm with $70 \%$ is in the third rank.

When the results are evaluated in terms of specificity criteria, Hoeffding Tree with $96 \%$ value, IBk with $95 \%$ value and Decision Stump algorithms with 93\% value are in the third place.

Looking at the ROC field values, it is seen that the best algorithm is Random Forest with 90\% AUC value. IBk with $82 \%$ AUC value is in the second place and LMT algorithm is in the third place with $79 \%$ AUC value. When all algorithms are evaluated according to their run times, the fastest ones are Decision Stump and IBk algorithms. After these, LMT algorithm comes.

As a conclusion, embedded or web based systems can be developed to help experts in early diagnosis of the worldwide common liver disease in light of this study.

Keywords: Liver Diseases, WEKA, Machine Learning Algorithms, Data Mining

Öz: Karaciğer hastalıkları dünya çapında oldukça yaygın görülen hastalıklardandır. Karaciğer hastalıkları vücutta büyük tehlikeler oluşturabilmektedir. Bu sebeplerden ötürü alkolden bağımsız karaciğer yağlanması, alkolik karaciğer yağlanması, hepatit $\mathrm{A}$, hepatit $\mathrm{B}$, hepatit $\mathrm{C}$, hepatit $\mathrm{D}$, karaciğer büyümesi, karaciğer kanseri, karaciğer ve intrahepatik safra kanalı kanseri, karaciğer yetmezliği ve siroz gibi karaciğer hastalıklarının mümkün oldukça erken bir aşamada teşhisi ve tedavisi hayati öneme sahiptir. Tıpta geleneksel teşhis yöntemleri hala kullanılmaktadır. Ancak bugün gelişen yapay zekâ teknolojileri sayesinde hastalık teşhis, tanı ve tedavi süreçlerinde hekimlere destek olacak güçlü araçlar sunulabilmektedir. Bu çalışmada WEKA veri madenciliği aracından faydalanılarak J48, Lojistik Model Ağac1 (LMT), Decision Stump, Hoeffding Tree, REP Tree, Random Forest, Random Tree ve IBk makine öğrenme algoritmaları Karaciğer Hasta Veri Seti (ILPD) üzerinde çalışılmıştır. Bu algoritmalar ile en iyi teşhis sonucuna ulaşılmaya çalışılmıştır. Çalışmada kullanılan makine öğrenme algoritmalarının performans ve başarılarını değerlendirmek için ilk önce karışıklık matrisleri oluşturulmuş daha sonra tıpta da genel geçerliliği kabul edilen ölçütlere göre hesaplamalar yapılmıştır. Bu algoritmaların ILDP veri seti üzerindeki performansları sırasıyla doğruluk, duyarlılık, özgüllük, ROC, MCC, Anma, Kesinlik ve F-Ölçütü kriterlerine göre hesaplanmıştır. Makine öğrenme algoritmalarından elde edilen en iyi modeller teşhise ve tedaviye yönelik geliştirilecek akıllı sistemlerin karar mekanizmalarını oluşturmak için kullanılabilmektedir. Bu çalışmada elde ettiğimiz modeller dünyada yaygın olarak görülen karaciğer hastalılarının tüm hastanelerde erken evrede yakalanmasını sağlayacak akıllı bir sistemin alt yapısını oluşturma potansiyeline sahiptir.

Anahtar Kelimeler: Karaciğer Hastalıkları, WEKA, Makine Öğrenme Algoritmaları, Veri Madenciliği

\section{Giriş}

Karaciğer insan vücudundaki en fazla göreve sahip olan aktif ve bir o kadar karmaşık organlardan biridir. Kanı ilaç, alkol gibi birçok yabancı ve toksik maddelerden arındırma, vücuttaki yağları sindirme, atıkları vücuttan uzaklaştırma ve safra üretme gibi hayati fonksiyonları yerine getirme açısından oldukça önemli bir organdır. Karaciğger hastalıkları dünya genelinde en sık rastlanılan hastalıklardandir.

Son yıllarda pek çok alanda büyük bir başarı ile kullanılan Yapay Zekâ teknolojilerinin bugün özellikle tıp alanında hastalıkların tanı, teşhis ve tedavi süreçlerinde sıkça kullanılmaya başlandığı görülmektedir. Bunun en önemli sebebi YZ teknolojilerinin altında yer alan ve Veri Madenciliğinin önemli bir parçası olarak kabul edilen makine öğrenme algoritmalarının örüntüler arasındaki gizli ilişkileri ortaya çıkarabilme gücüdür. Bu sayede benzer semptomlar gösteren, belirsizliklerin yoğun yer aldığ 1 ve birbirinden ayırt edilmesi güç hastalıkların teşhisinde çok ciddi oranlarda başarı sağlanabilmektedir.

$\mathrm{Bu}$ çalışmada karaciğer hastalıklarının teşhisine yönelik makine öğrenme algoritmaları çalışılmış ve sonuçları, literatürde bu konuda yapılan diğer çalışmalar ile karşılaştırılmıştır. 


\section{Materyal ve Yöntem}

\section{Karaciğer Veri Seti}

$\mathrm{Bu}$ çalışmada kullanılan veri seti, http://archive.ics.uci.edu/ml/index.php Internet adresinden ücretsiz olarak erişilebilen ve herkesin kullanımına açık olan UCI Machine Learning Respository veri tabanında bulunan Karaciğer Hastalığ 1 Veri Seti (Indian Liver Patient Dataset (ILPD))'dir.

$\mathrm{Bu}$ veri seti 583 hasta kaydından oluşmaktadır. Bu hastalardan 416 tanesi karaciğer hastası olup 167 tanesi diğer hastalardır. Veri seti Hindistan'ın Andhra Pradesh'in kuzey doğusunda toplanmıştır. Bu veri seti 441 erkek hasta kaydı ve 142 kadın hasta kaydını içermektedir. Erkek hastaların 324 tanesi karaciğer hastası iken kadın hastaların 92 tanesi karaciğer hastasıdır. Veri setinde yaş1 89'u aşan her hasta "90" yaş olarak listelenmiştir.

Veri kümesinde toplam 10 özelik için denekler üzerinde ölçümler yapılmıştır. 11. özellik ise hastalık durumunun olup olmadığının gösterildiği ve tıbbi uzmanlar tarafından oluşturulan alandır. Bu özelikler ve sahip oldukları veri tipleri Tablo 1' de detaylı olarak verilmiştir. Veri setinde kullanılan özelliklere ait istatistik bilgiler (ortalama, standart sapma, minimum, maksimum ve eksik değerler) ise Tablo 2'de sunulmuştur.

Tablo 1: Karaciğer Hasta Veri Setinin Özellik Bilgileri

\begin{tabular}{ccc}
\hline Özellikler & Açıllaması & Veri Tipi \\
\hline Age & Hastanın Yaşı & Numeric \\
Gender & Hastanın Cinsiyeti & Nominal \\
Total Bilirubin & Toplam Bilirubin & Real \\
Direct Bilirubin & Doğrudan Bilirubin & Real \\
Alkaline Phosphotase & Alkalen Fosfataz & Numeric \\
Alamine Aminotransferase & Alanin Aminotransferaz & Numeric \\
Aspartate Aminotransferase & Aspartat Aminotransferaz & Numeric \\
Total Protiens & Toplam Protein & Real \\
Albumin & Albümin & Real \\
Albumin/Globulin Ratio & Albümin/Globülin Oranı & Real \\
\hline Selector Field & Sinıf Bilgisi & Nominal \\
\hline
\end{tabular}

Tablo 2: Karaciğer Hasta Veri Setinde Kullanılan Özelliklerin İstatistik Bilgileri

\begin{tabular}{cccccc}
\hline Özelik Adı & Ortalama & Standart Sapma & Minimum & Maksimum & Eksik Değer Sayıs1 \\
\hline Yaş & 44.746 & 16.19 & 4 & 90 & 0 \\
Cinsiyet & & & & & \\
Toplam Bilirubin & 3.299 & 6.21 & 0.4 & 75 & 0 \\
Doğrudan Bilirubin & 1.486 & 2.808 & 0.1 & 19.7 & 0 \\
Alkalin Fosfataz & 290.576 & 242.938 & 63 & 2110 & 0 \\
Alanin Aminotransferaz & 80.714 & 182.62 & 10 & 2000 & 0 \\
Aspartat Aminotransferaz & 109.911 & 288.919 & 10 & 4929 & 0 \\
Toplam Protein & 6.483 & 1.085 & 2.7 & 9.6 & 0 \\
Albümin & 3.142 & 0.796 & 0.9 & 5.5 & 0 \\
Albümin/Globülin Oranı & 0.947 & 0.318 & 0.3 & 2.8 & 4 \\
\hline Sinff & & & & & \\
\hline
\end{tabular}

Turkish Studies - Applied Sciences, 15(1) 


\section{Veri Setine Uygulanan Ön İşlemler \\ - $\quad$ Eksik verilerin giderilmesi}

UCI veri deposundan indirilen veri setinde Albümin/Globülin oranı alanına ait 4 veri eksik olduğu görülmüştür. Daha iyi bir sınıflandırma yapma adına bu eksikliği Albümin/Globülin oranı alanındaki diğer verinin ortalama değerinin $(0,94)$ kullanılması ile giderilmiştir.

\section{- $\quad$ Normalize filtresi}

Normalize yöntemin amacı, veri setindeki veriler arasında farklılığın çok fazla olduğu durumlarda verileri tek bir düzen içerisinde ele almak ve verilerin birbiri ile karşılaştırılabilirliğini kolaylaştırmaktır (url 29). Bu yolla veriler [0,1] arası değerler alarak normalleştirilmiştir.

\section{- $\quad$ SMOTE filtresi}

Dengesiz bir dağılım gösteren ILPD veri setinin sınıflandırması yapılırken daha iyi sınıflandırma sonuçlarına ulaşmak için tercih edilen bir diğer filtre ise SMOTE (Synthetic Minority Oversampling Technique) filtresidir. Bu filtre $\sim 79 \%$ karaciğer hastası olan, $\sim 21 \%$ Karaciğer hastas1 olmayan veri setini daha dengeli hale getirmek için kullanılmıştır.

SMOTE filtresini uygulamak için azınlık durumunda olan (no) sınıfi örneği alınır ve sınıf türü yapay olarak çoğaltılır. Çoğaltma yöntemi için azınlık durumundaki sınıfın k komşusunun herhangi birine ya da tümüne bakılarak sentetik (suni) örnekler oluşturulur. Böylece azınlık sınıfı suni örneklerle dengelenmiş olur.

\section{- 10 Kat Çapraz Doğrulama}

Makine öğrenme algoritmalarını test etmek için kullanılan yaygın yöntem "Cross Validation" Çapraz Doğrulama tekniğidir. Bu çalışmada kullanılan makine öğrenme algoritmaları test edilirken çapraz geçerlilik yöntemi "10 katlı" olarak uygulanmıştır. Veri seti 10 parçaya bölünür. İlk parça test işlemi için diğer parçalar ise eğitim için kullanılmaktadır. Yöntem tüm parçalar bitene kadar her bir parçayı sırasıyla test ve diğerlerini eğitim için kullanmaya devam eder. Başka bir deyişle 10 parçalık bir veri setinin her parçası üzerinde 10 kez çalışmış olacaktır. Bu 10 kat çaprazlama işlemi neticesinde ortaya çıkan 10 hata değerinin ortalaması alınarak ortalama hata oranı bulunur.

\section{Araştırma Bulguları}

Veri seti üzerinde kullanılan bir makine öğrenmesi algoritmasının, sınıflandırma işlemi sonucunda oluşturduğu modelin performansını ve başarısını değerlendirmek için kullanılan bir takım genel geçer ölçütler vardır.

$\mathrm{Bu}$ ölçütlerin hesaplanmasında Tablo 3'de verilen karışıklık matrisi (confusion matrix) kullanılır. Karışıklık matrisi diğer bir adıyla hata matrisi, tahminlerin doğruluğu hakkında bilgi veren $2 \times 2$ 'lik bir matristir. Sınıflandırma sonucu oluşan modelin gerçek değerleriyle ile tahmin edilen değerlerinin karşılaştırılmasına olanak sağlar.

Tablo 3: Karıșıklık matrisi

\begin{tabular}{cccc}
\hline & & \multicolumn{2}{c}{ Tahmin Edilen Sınıf } \\
& & Pozitif $(\mathrm{P})$ & Negatif(N) \\
\hline Gerçek Sınıf & Pozitif $(\mathrm{P})$ & TP & FN \\
& & (True positive) & (False negative) \\
\cline { 2 - 4 } & Negatif(N) & FP & TN \\
& & (False positive) & (True negative) \\
\hline
\end{tabular}

www.turkishstudies.net/appliedsciences 
Karışıklık matrisindeki "True Positive (TP)" doğru tahmin edilen pozitif sınıf değerini, "False Negative (FN)" yanlış tahmin edilen negatif sınıf değerini, "False Positive (FP)" yanlış tahmin edilen pozitif sınıf değerini, "True Negative (TN)" ise doğru tahmin edilen negatif sınıf değerini temsil eder (Kaya 2017).

$\mathrm{Bu}$ çalışmada kullanılan her bir makine öğrenme algoritması ile elde edilen modelin kendine ait bir karışıklık matrisi vardır. Bu değerler kullanılarak algoritmaların performansını yani bir diğer deyişle karaciğer verileri üzerinden hastalığ koyulabilmektedir. Bunun için belirli ölçütlere dayalı hesaplamalar yapılmıştır. Bu ölçütlerin sırasıyla neler olduğu ve nasıl hesaplandığı ile ilgili aşağıda genel bilgi verilmiştir. Kullanılan ölçütler şunlardır:

- Doğruluk (Accuracy)

- Duyarlılık (Sensitivity)

- Özgüllük (Specificity)

- ROC (Receiver Operating Characteristics)

- MCC (Matthews Correlation Coefficient)

- Anma (Recall)

- Kesinlik (Precision)

- F-Ölçütü (F-Measure)

1) Doğruluk (Accuracy): Tüm doğru tahmin edilen değerlerin, bütün sonuçlara olan oranıdır.

$$
\text { Doğruluk }=\frac{\text { TP }+ \text { TN }}{\text { TP }+ \text { TN }+ \text { FP }+ \text { FN }}
$$

2) Duyarlıık (Sensitivity): Duyarlılık ve TP rate (True positive oranı), doğru tahmin edilen pozitif sınıf değerlerinin, tüm pozitif sınıf değerlerine oranıdır. Yani gerçekte hasta olanlarının ne kadarını saptayabildiğini gösterir. Pozitif kararın doğru olma olasıllı̆ıdır.

$$
\text { Duyarlılık }=\text { TP Oran } ı=\frac{\text { TP }}{\text { TP }+ \text { FN }}
$$

3) Özgüllük (Specificity): Doğru tahmin edilen negatif sınıf değerlerinin, tüm negatif sınıf değerlerine oranıdır. Gerçekte sağlam olanlardan ne kadarının doğru olarak (sağlamnormal) saptayabildiğini gösterir. Negatif kararın doğru olma olasıllı̆ını gösterir.

$$
\text { Özgüllük }=\frac{\text { TN }}{\text { TN }+ \text { FP }}
$$

4) ROC (Receiver Operating Characteristics): ROC eğrisi bir tanı testine ilişkin duyarlık ve özgüllük değerleri arasındaki ilişkiyi grafiksel olarak gösterir. ROC eğrisi doğru pozitif orana (duyarlık) karşın yanlış pozitif oranların (1-özgüllük) noktalanarak çizilmesiyle elde edilir. Bir diğer ifadeyle TP oranı ile FP oranını arasındaki ilişkinin grafiksel olarak gösterimidir. Grafikte eğri altında kalan alan (AUC) değeri 1'e yaklaştıkça tanı değeri yükselmektedir.

5) MCC (Matthews Correlation Coefficient): MCC, gerçek sınıf ve tahmin edilen ikili sinıflandırmalar arasında bir korelasyon katsayısıdır; -1 ile +1 arasında bir değer alır.

$$
\mathbf{M C C}=\frac{\mathbf{T P} * \mathbf{T N}-\mathbf{F P} * \mathbf{F N}}{\sqrt{(\mathbf{T P}+\mathbf{F P})(\mathbf{T P}+\mathbf{F N})(\mathbf{T N}+\mathbf{F P})(\mathbf{T N}+\mathbf{F N})}}
$$

6) Anma (Recall): Doğru tahmin edilen pozitif sınıf değerinin, bütün gerçek pozitif sınıf değerlerine oranıdır.

$$
\text { Anma }=\frac{\text { TP }}{\text { TP }+ \text { FN }}
$$

7) Kesinlik (Precision): Doğru tahmin edilen pozitif sınıf değerinin, bütün pozitif olarak tahmin edilen sınıf değerlerine oranıdır. 


$$
\text { Keskinlik }=\frac{\text { TP }}{\text { TP }+ \text { FP }}
$$

8) F-Ölçütü (F-Measure): Duyarlılık ile kesinlik ölçütlerini beraber değerlendirilebilmek için kullanılan F-Ölçütü, bu iki ölçütün harmonik ortalamasıdır.

$$
\text { F }- \text { Ölçüsü }=2 * \frac{\text { TP Oranı } * \text { Keskinlik }}{\text { TP Oranı }+ \text { Keskinlik }}
$$

Bu çalışmada, WEKA veri madenciliği programında yer alan J48, Lojistik Model Ağacı (LMT), Decision Stump(Karar Kütüğü), Hoeffding Tree, REP Tree, Random Forest, Random Tree ve IBk makine öğrenme algoritmaları ile ILPD veri seti üzerinde çalışılmıştır. Bu algoritmaların sınıflama performansları yani teşhis güçleri yukarda izah edilen değerlendirme ölçüleri kullanılarak teker teker hesap edilmiş (Tablo 4) ve karşılaştırılmıştır. Farklı makine öğrenme algoritmaları ILPD veri setine uygulanmadan önce bir takım veri önişleme adımları gerçekleştirilmiştir. İlk olarak veri setindeki eksik değerler ortalama yöntemiyle giderilerek eksiksiz hale getirilmiștir. Ardından veri seti, veriler arasındaki farkı azaltan normalize filtresi ve sınıflar arasındaki dengesiz dağılımı gidermek için sentetik veri üreten SMOTE filtreleriyle işlem görmüştür. Son olarak sınıflandırma işleminin güvenirliğini artırmak için makine öğrenme algoritmaları 10 kat çapraz geçerlilik yöntemi ile eğitilmiş ve test edilmiştir.

Tablo 4: Kullanılan algoritmaların performans değerleri

\begin{tabular}{cccccccccc}
\hline ALGORİTMA & Doğruluk & Duyarlılık & Özgüllük & ROC & MCC & Anma & Precision & $\begin{array}{c}\text { F- } \\
\text { Measure }\end{array}$ & $\begin{array}{c}\text { Çalısma } \\
\text { Süresi } \\
\text { (sn) }\end{array}$ \\
\hline J48 & & & & & & & & & \\
LMT & 0,744 & 0,680 & 0,808 & 0,755 & 0,493 & 0,744 & 0,748 & 0,743 & 0,08 \\
Decision Stump & 0,671 & 0,675 & 0,801 & 0,787 & 0,480 & 0,738 & 0,742 & 0,737 & 0,58 \\
Hoeffding Tree & 0,691 & 0,416 & 0,926 & 0,657 & 0,397 & 0,671 & 0,731 & 0,648 & 0 \\
REP Tree & 0,713 & 0,704 & 0,957 & 0,741 & 0,451 & 0,691 & 0,766 & 0,668 & 0,03 \\
Random Forest & 0,819 & 0,764 & 0,722 & 0,761 & 0,426 & 0,731 & 0,713 & 0,713 & 0,05 \\
Random Tree & 0,738 & 0,724 & 0,753 & 0,902 & 0,641 & 0,819 & 0,822 & 0,818 & 0,33 \\
\hline IBk & 0,816 & 0,688 & 0,945 & 0,816 & 0,477 & 0,738 & 0,738 & 0,738 & 0,02 \\
\hline
\end{tabular}

Tablo 4 incelendiğinde tüm algoritmaların ortalama doğruluk değerleri \%74'ün üzerinde olduğu görülmektedir. Random forest algoritması \%81.9 ile en yüksek doğruluk sonucuna sahiptir. $\mathrm{Bu}$ algoritmanın en yakın takipçisi IBk algoritmasıdır ve \%81.6 ile en iyi ikinci sonucu vermektedir. Çalışmada J48, LMT ve Random Tree algoritmaları \%74'lerdeki doğruluk değerleri ile üçüncü sırada gelmektedir. Hoeffding Tree ise \%69.1 doğruluk oranıyla dördüncü, Decision Stump \%67.1 ile son sirada yer almaktadır.

Duyarlılık ölçütüne göre tüm algoritmalar değerlendirildiğinde en iyi sonucu veren algoritma \%76 değeriyle Random Forest algoritmasıdır. İkinci \%72 ile Random Tree, üçüncü sırada ise \%70 değeri ile REP Tree algoritması yer almaktadır.

Sonuçlar özgüllük ölçütü açısından değerlendirildiğinde ilk sırayı \%96 değeri ile Hoeffding Tree, ikinci sırada \%95 değeri ile IBk, üçüncü sırada ise \%93 değeri ile Decision Stump algoritmaları yer almaktadır.

ROC alanı değerlerine bakıldığında yine en iyi algoritmanın \%90 AUC değeri ile Random Forest olduğu görülmektedir. \%82 AUC değeri ile ikinci sırada IBk ve \%79 AUC değeri ile LMT algoritması üçüncü sırada yer almaktadır.

Çalışma süreleri açısından tüm algoritmalar değerlendirildiğinde en hızlı Decision Stump ve IBk algoritmaları ardından LMT algoritması gelmektedir. 


\section{Tartışma ve Sonuç}

Makine öğrenme algoritmaları pek çok alanda olduğu gibi sağlık alanında da başarılı bir şekilde sıklıkla kullanılmaktadır. Günümüzde makine öğrenmesi ve veri madenciliği yöntemleriyle doktorların doğru karar almalarına yardımcı olacak veya kararlarını destekleyecek pek çok hastalığın teşhisinde, sınıflandırılmasında, tahmin edilmesinde kullanılacak akıllı uygulamalar sağlık alanında geliştirilebilmektedir.

$\mathrm{Bu}$ tez çalışması insan yaşamını ve yaşam kalitesini etkileyen oldukça bulaşıcı ve tehlikeli türleri olan karaciğer hastalıklarının erken ve yüksek doğrulukla teşhisini kolaylaştırmaya odaklanmıştır. Dünya genelinde yaygın olarak görülmekte olan karaciğer hastalıkları günümüzde birçok araştırmaya konu olmuştur. Bu çalışmada UCI makine öğrenme veri tabanında yer alan Indian Liver Patient Dataset (ILPD) adlı veri seti kullanılmıştır. Bu veri seti evrensel olarak karaciğer hastalığının teşhisinde kullanılan değişkenleri içeren gerçek hastalara ait kayıtlardan oluşmaktadır.

Bu çalışmada elde edilen sonuçlar alan yazındaki diğer çalışmalar ile karşılaştırmalı olarak Tablo 5'de incelenmiştir. Buna göre; Dwivedi vd. (2017) ILPD veri setini WEKA ve Tangara araçlarında yer alan Random Forest algoritmasının da içinde bulunduğu 6 farklı algoritma ile çalıştılar. Random Forest algoritmasının doğruluk değerini \%67.5 olarak buldular.

Gulia vd. (2014) ILPD veri setini WEKA aracında J48 ve Random Forest algoritmalarının da içinde bulunduğu 5 farklı algoritmayla çalışarak özellik seçimi (Feature Selection) uyguladılar. $\mathrm{Bu}$ işlem sonucunda seçilen özellikler ile J48 algoritmasının doğruluk değeri \%70.6 olurken en iyi sonucu veren Random Forest algoritmasının doğruluk değerini ise \%71.8 olarak buldular.

Muthuselvan vd. (2018) ILPD veri setini WEKA aracinda J48 ve Random Forest algoritmalarının da içinde bulunduğu 5 farklı algoritmayla çalıştılar. Sonuç olarak J48 algoritmasının doğruluk değerini \%71.2, en iyi sonucu veren Random Forest algoritmasının doğruluk değerini ise \%74.2 olarak buldular.

Pahareeya vd. (2014) ise ILPD veri setini kullanarak WEKA aracında 10 kat çapraz doğrulama ve aşırı örnekleme önişlemi 4 farklı makine öğrenme algoritmasını üzerinde çalıştılar. Önişlemlerden önce orijinal veri seti ile J48 algoritması ile \%68.39, Random forest algoritmasıyla ise \%71.5 oranında doğruluk değeri elde ettiler. Ancak en iyi sonucuna \%200 aşırı örnekleme önişlemi ile J48 algoritmas1 \%87.24, Random Forest algoritması ile \%89.11 doğruluk değerlerine ulaştılar.

Tablo Hata! Belgede belirtilen stilde metne rastlanmadı.: Çalışmanın literatürdeki benzer çalışmalar ile sadece doğruluk değeri üzerinden karşılaştırılması

\begin{tabular}{cccc}
\hline Araştırmacılar & Araç & Algoritma & Doğruluk Oranı \\
\cline { 1 - 3 } Pahareeya et al. (2014) & WEKA & J48 & $\% 87.2$ \\
& & Random Forest & $\% 89.1$ \\
Gulia et al. (2014) & WEKA & J48 & $\% 70.6$ \\
& & Random Forest & $\% 71.8$ \\
Muthuselvan et al. (2018) & WEKA & J48 & $\% 71.2$ \\
& & Random Tree & $\% 74.2$ \\
Dwivedi et al. (2017) & WEKA & Random Tree & $\% 67.5$ \\
\hline Bu çalı̧̧mada & WEKA & J48 & $\% 74.4$ \\
& & LMT & $\% 73.8$ \\
& & Decision Stump & $\% 67.1$ \\
& & Hoeffding Tree & $\% 69.1$ \\
& & REP Tree & $\% 71.3$ \\
& & Random Forest & $\% 81.9$ \\
& & Random Tree & $\% 73.8$ \\
& & IBk & $\% 81.6$ \\
\hline
\end{tabular}

Turkish Studies - Applied Sciences, 15(1) 
Bu çalışmanın 1şı̆̆ında şu önerilerde bulunulabilir:

$\mathrm{Bu}$ çalışma sağlık alanında karaciğer hastalıkları üzerinde yapılmıştır. Veri seti olarak ILPD kullanılmıştır. Benzer çalışmalar farklı çalışma alanlarındaki veri setleri üzerine yapılabilir.

Sistem başarımını yükseltmek için daha farklı önişleme teknikleri denenebilir. Farklı veri madenciliği araçlarında ve farklı algoritmalar kullanılarak başarım değerlendirmeleri yapılabilir.

Sağl1k alanında yapay zekânın daha aktif kullanılacağı öngörülen yakın çağda yeni veri madenciliği ve makine öğrenme algoritmaları geliştirilerek ihtiyaca yönelik kullanılabilir.

En önemlisi makine öğrenme algoritmalarından faydalanılarak başta karaciğer hastalıkları olmak üzere pek çok hastalı̆ğn teşhis ve tedavisine yönelik doktorlara destek olacak aklıllı karar destek sistemleri geliş̧irilebilir.

\section{KAYNAKÇA}

Dwivedi, A., Dewangan, A.K. and Shrivas, A. K. (2017). "Analysis and Comparison of Models for Classification of Diabetic Disease". International Journal for Research in Applied Science \& Engineering Technology (IJRASET), 5(V), 2111-2114.

Gulia, A., Vohra, R., and Rani, P. (2014). "Liver Patient Classification Using Intelligent Techniques". (IJCSIT) International Journal of Computer Science and Information Technologies, 5 (4) , 5110-5115.

Kaya, Y. (2017). Motokaravan sigortacılĭg tahmin modellemesi ve uygulanan yöntemlerin karşılaş̧tırlması, Yüksek Lisans Tezi, Beykent Üniversitesi Fen Bilimleri Enstitüsü, İstanbul.

Muthuselvan, S., Rajapraksh, S., Somasundaram, K. and Karthik, K. (2018). "Classification of Liver Patient Dataset Using Machine Learning Algorithms". International Journal of Engineering \& Technology, 7(3.34), 323-326.

Pahareeya, J., Vohra, R., Makhijani, J. and Patsariya, S. (2014). "Liver Patient Classification using Intelligence Techniques". International Journal of Advanced Research in Computer Science and Software Engineering, 4(2), 295-299.

url http://bilgisayarkavramlari.sadievrenseker.com/2012/01/29/istatistiksel-normallestirmestatistical-normalisation/ (17.02.2019) 